\title{
TYPES OF EDUCATIONAL AND PROFESSIONAL TASKS USED FOR DOCTORS' TRAINING
}

\section{(C) 2018}

Astanina Svetlana Yurievna, candidate of pedagogical sciences, professor of Medical Pedagogy, Philosophy and Foreign Languages Department, head of Scientific, Methodological and Educational Activities Department Russian Medical Academy of Continuing Professional Education (Moscow, Russian Federation)

Abstract. The paper deals with the problem of the fundamental training of doctors on the basis of solving various groups of educational and professional tasks in continuing medical education. Analysis of various scientists' views allowed the authors to determine that the continuity and integrity of education is ensured by continuity in solving educational and professional tasks, formed from professional tasks. Due to the fact that in health care there is a fairly rapid introduction of the basic sciences (molecular biology, biophysics, biochemistry) achievements results into the processes of medical care, the knowledge-intensiveness of labor functions increases, their diversity increases, which leads to an increase in professional tasks. The interrelation of types and classes of educational and professional tasks ensures the continuity of the content of the fundamental training of doctors. Intra-subject relationships are formed between groups of educational and professional tasks (invariant and variable), ensuring the integrity of the content of the biological training of doctors. Division of educational and professional tasks into classes and types allows to systematize the content of fundamental training of doctors in accordance with the actual educational needs of the trained doctors and the requirements of practical public health, which in turn ensures continuity, expressed in the sequence and consistency of the content, forms and methods of the educational process; in the consistency and coherence of training at various stages of medical education.

Keywords: fundamental training of doctors; additional professional education; continuity of medical education; continuity of vocational education; biomedical training; professional tasks; educational and professional tasks; types of educational and professional tasks.

\section{СТАНОВЛЕНИЕ ПРОФЕССИОНАЛЬНОЙ ИДЕНТИЧНОСТИ КАК ФАКТОР ПРОЕКТИРОВАНИЯ КАРЬЕРНОЙ СТРАТЕГИИ СОВРЕМЕННОГО СТУДЕНТА ВУЗА}

(C) 2018

Беркутова Диана Искандеровна, кандидат педагогических наук,

доцент кафедры методик математического и информационно-технологического образования

Громова Екатерина Михайловна, кандидат педагогических наук, доцент кафедры методик математического и информационно-технологического образования

Горшкова Татьяна Анатольевна, кандидат педагогических наук, доцент кафедры методик математического и информационно-технологического образования Ульяновский государственный педагогический университет имени И.Н. Ульянова (2. Ульяновск, Российская Федерачия)

Аннотация. В статье акцентировано внимание исследователей на проблеме становления профессиональной идентичности современной молодежи, которое, по мнению авторов, напрямую связано с проектированием карьерной стратегии. Авторами проанализированы основные теоретические подходы к сущности понятий «профессиональная идентичность», «личная профессиональная перспектива» и «карьерная стратегия». В статье представлены результаты исследования авторским коллективом профессиональных планов современных студентов педвуза в контексте планирования ими профессиональной карьеры. Экспериментальную выборку респондентов составили студенты очной формы обучения факультета физико-математического и технологического образования ФГБОУ ВО «Ульяновский государственный педагогический университет имени И.Н. Ульянова». Диагностирование респондентов проводилось по методике Н.С. Пряжникова «Личная профессиональная перспектива», способствующей стимулированию размышлений молодых людей над сложными многоаспектными мировоззренческими проблемами бытия, выбора профессионального пути, построения успешной карьеры и провоцированию индивидуальных консультаций ценностно-смыслового характера, а также по методике Э. Шейна «Якоря карьеры», которая используется для определения ведущих профессиональных мотивов. Полученные результаты исследования подвергнуты тщательному анализу. В статье приводятся результаты проведенных диагностик, доказывающие, что личная профессиональная перспектива и карьерная стратегия тесно взаимосвязаны. Материалы, которые были получены в ходе представленного исследования, могут служить отправной точкой для дальнейших разработок теоретического и практического характера по проблеме проектирования карьерной стратегии современной молодежи.

Ключевые слова: профессия; профессиональное самоопределение; профессиональные планы; карьерная стратегия; профессиональная идентификация; профессиональная идентичность; ценностные ориентации; информационная культура; студенчество; методика Н.С. Пряжникова «Личная профессиональная перспектива»; методика Э. Шейна «Якоря карьеры». 
Проектирование профессиональной карьеры молодым человеком, его самоопределение и интеграция в сферу труда представляют в настоящее время особый интерес для исследователей. В первую очередь, это объясняется тем, что современная молодежь как социальная группа находится в крайне противоречивых отношениях с обществом, одновременно являясь, с одной стороны, объектом трансляции культурных ценностей, а с другой - носителем инновационных преобразований. К наиболее мобильной части молодежи относится студенчество, которое обладает особой ценностью для общества, является тем ресурсом специалистов, который в скором времени пополнит экономику России квалифицированными кадрами.

Как показывает опыт, планирование карьеры молодежью является наиболее эффективным в период социально-экономической стабильности. Но при резком переходе от данного состояния к состоянию неопределенности, а также в условиях многочисленных культурных, социальных, экономических вызовов характерной чертой социокультурного пространства современной России стало наличие противоречий, кризисов. В этот период обществу в целом, а в частности студенческой молодежи, достаточно сложно адаптироваться в новой обстановке, наметить для себя именно ту стратегию, которая позволит достигнуть поставленной цели в кратчайшие сроки с затратой минимальных ресурсов. Студенчество в этом плане стоит перед необычайно трудной задачей. При отсутствии социальной поддержки со стороны государства и при неорганизованной молодежной политике высока вероятность того, что профессиональный потенциал молодых людей может быть реализован не в полной мере. Отсутствие адекватных современности механизмов профориентации, слабое участие государства в трудоустройстве выпускников после окончания учебного заведения существенно затрудняют проектирование и практическую реализацию карьерных стратегий обучающихся. А между тем именно в процессе приобретения знаний и профессионального опыта в период учебы у студентов намечаются четкие жизненные цели, а также конкретные пути и способы их достижения, формируются ценностные ориентации, базируясь на которых студенты прогнозируют свое будущее, выстраивают целостную стратегию своего жизненного пути [1].

Поэтому, на наш взгляд, проектирование карьерной стратегии современной молодежью напрямую связано со становлением ее профессиональной идентичности.

В настоящее время повышенное внимание современных исследователей из различных областей гуманитарных наук, как зарубежных (Р. Браун, Дж. Келли, К. Левин, У. Найсер, Г. Стефенсон, А. Тэшфел, Л. Фестингер, С. Хинкл, Э. Эриксон и др.), так и отечественных (Г.М. Андреева, Т.М. Буякас, М.Н. Губогло, П.С. Гуревич, Л.М. Дробижева, М.В. Заковоротная, А.В. Кузьмин, Н.М. Лебедева, О.В. Лукьянов, В.С. Малахов, О.Ю. Малинова, Д.А. Орлов, Л.М. Путилова, Т.Г. Стефаненко, М.В. Шакурова, Л.Б. Шнейдер и др.), направлено на вопросы, связанные со становлением социальной идентичности, выделением ее структурных компонентов, поиском путей и механизмов ее формирования.
Проведенный нами информационный поиск и анализ научной литературы показал, что в самом общем виде большинство ученых понимают под социальной идентичностью отнесение человеком себя к определенной группе. Так, нам представляется наиболее точным следующее определение: «Социальная идентичность - это феномен, возникающий на основании осознания личностью своей принадлежности к разнообразным социальным группам, в которые человек включается в ходе своей жизнедеятельности» [2, с. 21-22]. Здесь важно отметить, на наш взгляд, что именно профессиональная идентичность выступает доминантой социальной жизнедеятельности личности. Правомерен и тот факт, что принадлежность человека к той или иной профессиональной группе формирует у него определенные ценностные ориентации и установки, напрямую способствуя развитию его социальной идентичности.

Опираясь на мнение социолога В.А. Ядова и его единомышленников, можно сказать, что профессиональный критерий является единственным в своем роде твердым критерием для выделения социальных единств людей.

Целесообразно заметить, что процесс профессионального самоопределения не заканчивается выбором профессии в юношеском возрасте, а продолжается в течение всей профессиональной жизни человека. Поэтому можно смело утверждать, что образно профессиональное самоопределение является прямой, а выбор профессии всего лишь точкой на этой прямой [3, с. 24]. Это обусловлено и тем фактором, что человек может, в силу разного рода обстоятельств, сменить сферу своей профессиональной деятельности (к примеру, получив иное образование в магистратуре, нежели он имел в результате бакалаврской подготовки), а также и тем, что в ходе развития науки и техники содержание конкретного труда претерпевает существенные изменения.

В свою очередь, в процессе становления профессиональной идентичности человек окунается в многомерность социального бытия, что демонстрируется в построении им пространственно-временной перспективы, конструирующей смысл жизни человека и объединяющей в себе широкий круг профессиональных и личностных жизненных ценностей и установок, целей, планов личности и в конечном итоге оказывающей влияние на формирование идентичности в целом. В психолого-педагогической литературе существует ряд синонимичных терминов и понятий, описывающих данную область внутреннего мира личности (К.А. Абульханова-Славская, М.М. Бахтин, Е.И. Головаха [4, с. 23], Р.М. Гинзбург, И.С. Кон, А.А. Кроник, К. Левин, Ж. Нюттен, Н.Н. Толстых, А.И. Федоров, Л. Франкл и др.).

Проведенный нами анализ отечественной психологической литературы позволяет сделать вывод, что основой термина «личная профессиональная перспектива» (ЛПП) являются исследования в плоскости проблемы профессионального консультирования (Н.Ф. Гейжян, Е.А. Климов, Г.Ф. Королькова, Н.С. Пряжников и др.). В то же время ЛПП предусматривает два основных аспекта при ее организации:

1) ценностно-смысловой аспект (обеспечивает ценностную сторону целеполагания и содержит систему ценностей, определяющих смысл жизни человека); 
2) пространственно-временной (наличие представлений о будущем, выраженных в жизненных и профессиональных целях и планах) [5, с. 117-136].

Многие ученые-исследователи видят непосредственную, тесную взаимосвязь ЛПП с тайм-менеджментом и выстраиванием жизненных планов личности, которые предполагают и определение целей, и выбор эффективных путей их достижения, и необходимых личностных ресурсов, осознание ценности и смысла реализации жизненных планов.

Для исследования перспектив профессиональноличностного развития сегодня широко применяется опросник, разработанный Н.С. Пряжниковым [6], который получил название ЛПП. Данная методика одновременно является и диагностирующей, и стимулирующей, поскольку способствует активизации раздумий испытуемых над сложными жизнеопределяющими вопросами, обдумыванием мировоззренческих установок, проблемами профессионального и саморазвития, постановки профессиональных целей. Методика побуждает личность к индивидуальным консультациям ценностного характера и позволяет оценить степень сформированности ЛПП, чтобы выделить проблемные точки и проработать их более детально. Личная профессиональная перспектива при этом, с нашей точки зрения, позволяет оценить когнитивный, эмоциональный и действенный компоненты готовности личности к профессиональному самоопределению, учитывая сформированность знаний о мире профессий и правилах профессионального выбора, уровень познания человеком самого себя, а также стратегическое и тактическое планирование конкретных шагов на пути достижения профессиональной цели. Анализ результатов, полученных по опроснику «Личная профессиональная перспектива» Н.С. Пряжникова, осуществляется на основе «контент-анализа», т.е. того, насколько подробно и аргументированно выполнены ответы на вопросы, выявлены или нет среди них противоречия.

Как уже отмечалось выше, для современного этапа развития отечественного и зарубежного образования характерен всплеск интереса исследователей к проблеме планирования профессиональной карьеры молодым специалистом. Однако без особого внимания, на наш взгляд, остается вопрос изучения особенностей построения карьеры молодым учителем выпускником педвуза. Нам представляется, что его решение тесно связано с формированием профессиональной идентичности личности.

Так, анализируя данные, полученные в результате опроса студентов факультета физико-математического и технологического образования ФГБОУ ВО «Ульяновский государственный педагогический университет имени И.Н. Ульянова» по методике ЛПП, мы выявили положительный факт: у всех студентов определена дальняя профессиональная цель, которая при этом согласована с другими важными жизненными целями. Однако детальный анализ результатов выявил и тревожный факт: данная профессиональная цель носит в большей степени характер мечты. Это обстоятельство свидетельствует, на наш взгляд, о низкой профессиональной идентичности студентов педагогического вуза, поскольку значительный процент опрошенных прогнозирует свое будущее в сфере предпринимательской деятельности и бизнеса, либо, как вариант, в сфере менеджмента, мечтая стать руководителем или управленцем в какой-либо фирме/организации, хотя и получают высшее образование по направлениям подготовки «Педагогическое образование» и «Профессиональное обучение».

Большинство психологических исследований, связанных с проблематикой жизненной перспективы личности, имеют достоверные доказательства того, что без ясного, четкого представления о своем будущем человек не способен в полной мере к целенаправленной саморегуляции своего поведения, к осуществлению долгосрочного планирования своей деятельности, к преодолению проблем, которые возникают у него в социальной и профессиональной жизни. Поэтому сегодня в образовании особенно актуальной становится проблема разработки эффективных форм, методов и техник формирования позитивной профессиональной идентичности у студентов педвуза с тем, чтобы в сферу образования пришел молодой учитель нового поколения, обладающий принципиально новым взглядом на проектирование образовательной среды.

При этом в современных условиях вхождения России в мировое цифровое пространство любое профессиональное развитие, а тем более профессиональное развитие педагога, не представляется возможным без формирования информационной культуры личности, поскольку глобальное информационное пространство позволяет эффективно войти в профессиональное сообщество: создать персональный сайт учителя, найти профессионалов-единомышленников, поделиться с ними опытом, достижениями, методическими разработками, поучаствовать в разнообразных сетевых конкурсах и олимпиадах и т.д. Примером тому служат портал «Единыйурок.рф», а также образовательный портал «Знанио», интернетпроект «Копилка уроков - сайт для учителей», проект «Инфоурок», информационно-образовательный ресурс «Педагогика XXI век» и др. В настоящее время стало возможным проведение дистанционных лекций и вебинаров и даже онлайн-конференций, в которых бакалавры и магистранты УлГПУ в рамках научно-исследовательской работы систематически принимают активное участие, например, Сетевая педагогическая конференция по формированию цифрового пространства детства «Сетевичок»; вебинар «Модернизация технологического образования: новые требования и новые возможности»; открытая веб-конференция для участников и организаторов Всероссийской акции по безопасному поведению детей в сети интернет «Сети, которые выбирают дети» и многие другие.

Сформированная информационная культура означает, что личность применяет информационные технологии для достижения целей в своей деятельности, в том числе профессиональной. При этом компьютерные системы, сети и программное обеспечение служат в качестве средств, с помощью которых профессионал может планировать свою работу, организовать поиск информации, структурировать её, использовать для коммуникации, т.е. представлять в виде, понятном другим людям: ученикам, коллегам и пр. Обобщая сказанное, отметим, что информационная культура - это умение человека использовать соответствующим образом весь набор информационных технологий в своей деятельности [7, с. 255]. 
В диссертационном исследовании Н.Н. Масленниковой $[8$, с. 51-55] выделены такие составляющие компоненты информационной культуры, как овладение компьютерной грамотностью; способность к овладению информационно-коммуникативными технологиями как новыми средствами для решения проблем; умение сотрудничать в режиме саморазвития, используя сети телекоммуникации; способность быстрее других отследить, оценить, понять предложенную информацию и включить её в процесс.

Информационная культура в условиях современного информационного общества является неотъемлемым компонентом профессионализма, поскольку способствует развитию не только профессиональных компетенций, но и становлению позитивной профессиональной идентичности.

Послание Президента Российской Федерации В.В. Путина к Федеральному Собранию в декабре 2016 года обозначило, что путь в цифровую экономику для России стал магистральным.

В августе 2017 года премьер-министром нашей страны Д.А. Медведевым было подписано распоряжение об утверждении программы «Цифровая экономика РФ», согласно которой развитие целесообразно осуществлять в рамках пяти приоритетных направлений, в том числе формирование исследовательских компетенций и технических заделов, образование и кадры. Следовательно, сегодня центральным становится вопрос о кадрах с необходимыми навыками, т.е. профессиональное образование сегодня должно быть направлено на формирование информационной культуры, инновационного мышления и др.

России сегодня, как никогда, необходимы молодые профессионалы, которые способны к быстрому, эффективному решению проблем, возникающих в процессе профессиональной деятельности, в том числе этического плана. Наличие таких кадров обусловлено подготовкой педагога как главного помощника в обретении этих ценностей. Следовательно, назрела потребность инновационного развития системы образования, и в первую очередь реформы высшего педагогического образования, поскольку от профессиональной компетентности и ценностных ориентаций учителя во многом зависит успешность любых преобразований.

Однако, как демонстрируют нам социологические опросы, а также диагностирование студентов ФГБОУ ВО «УлГПУ им. И.Н. Ульянова», проведенное после прохождения педагогической практики и участия в конкурсе профессионального мастерства - чемпионате World Skills Russia [9], несмотря на то, что абсолютно все студенты осознают, в какое учебное заведение они поступили и какую профессию получают, $38 \%$ студентов заявили о своей проблеме неумения общаться с детьми, устанавливать с ними доверительные отношения и конструктивно выходить из конфликтных ситуаций (справедливости ради отметим, что ни один из опрошенных респондентов не заявил о своем нежелании взаимодействовать с обучающимися). Кроме того, к трудностям профессиональной деятельности и своей адаптации в качестве молодого профессионала опрошенные отнесли боязнь публичных выступлений (16\%) и неумение противостоять стрессам (24\%). Действительно, в России, по данным социологических исследований, лишь незначительный процент выпускников готов работать в образовательном учреждении. Ситуация осложняется тем, что выпускник-магистр, к примеру, может иметь подготовку по иному профилю, нежели полученную им в бакалавриате.

О требующих незамедлительного решения проблемах проектирования профессиональной карьеры молодым педагогом сегодня свидетельствует невысокий статус профессии учителя в обществе, ограниченные возможности карьерного роста, деформированная возрастная структура педагогических кадров [10, c. 19-22].

Сложившаяся ситуация имеет основания. Содержание образования во многих педвузах страны занимают в основном теоретические знания, и это создает определенную сложность для применения этих знаний в реальной практической деятельности. А в настоящее время необходимыми и важными становятся не сами по себе получаемые теоретические знания, а умение их использовать в различных ситуациях. Еще более важным становится знание о том, как эту информацию добывать и обрабатывать. Как справедливо отмечает А.А. Вербицкий, знания, умения и навыки, полученные в процессе обучения, должны превращаться в средства решения задач профессиональной деятельности [11]. В теории, по мнению многих ученых, компетентностный подход в высшем профессионально-педагогическом образовании призван реализовать целый ряд положительных аспектов, однако на практике это лишь декларируется. На наш взгляд, формирование информационной культуры педагога как раз и может стать одним из путей решения данной проблемы.

Подчеркивая важность вышесказанного, следует отметить, что действительность современного российского образования предъявляет к студенту педагогического вуза определенные требования в вопросе обоснованного выбора в сочетании с высокой долей ответственности за сделанный выбор, несмотря на условия неопределенности завтрашнего дня в целом и в профессии в частности. Одновременно с этим жизненная перспектива личности является отражением не только ее способности прогнозировать и планировать свою жизнь, но и дает возможность проекции на настоящее личности, определяя степень ее удовлетворенности этим настоящим. Заметим при этом, что удовлетворенность настоящим во многом зависит от его соответствия будущим устремлениям, перспективам и планам личности, степени идеальности и реальности этих планов, готовности и способности личности к их реализации.

Социологические исследования убедительно доказывают, что у современной молодежи происходит изменение вектора траектории направленности жизненных ориентаций от социальной (коллективистской) составляющей к более индивидуальной. Это смело можно отнести и к вопросу ценностей молодых людей в плане проектирования профессиональной карьеры. Желание успешной карьеры, стремление к ней является естественным в условиях современного общества, при этом большинство опрошенных ясно осознают значимость и важность образования для достижения поставленной цели. Нельзя не обратить внимания и на тот факт, что материальное 
благосостояние сегодня стало цениться гораздо выше свободы, ценность оплаты труда стала преобладать над ценностью интересной работы [12, с. 37-43].

Согласно сформировавшейся точке зрения большинства ученых-исследователей, изучающих молодежь как специфическую социальную группу, одной из ее ключевых характеристик является «отношение к труду» - компонент, являющийся, по сути, совокупностью профессионально-трудовых ценностей. В настоящее время он складывается под воздействием целого ряда неблагоприятных социокультурных факторов окружающей действительности. В частности, можно выделить чрезмерное стремление к личному материальному благополучию, возможности обогащения при минимальной затрате средств, ценой легких усилий, отсутствие общей культуры, падение нравственных ограничений и другие. Вследствие этого у многих молодых людей «... не формируется активная жизненная позиция, отсутствуют желание полноценного труда, учебы, стремление внести свой вклад в дело дальнейшего развития общества» [13].

Как показывает опрос, проведенный нами среди студентов факультета физико-математического и технологического образования ФГБОУ ВО «УлГПУ имени И.Н. Ульянова», для определенной части респондентов (11\%) труд утратил общественную ценность и рассматривается в настоящее время лишь как средство удовлетворения личных материальных потребностей [14]. Признание трудовой деятельности в качестве важнейшей человеческой ценности, имеющей неоспоримое значение для прогрессивного развития общества, лишено для большинства смысла. Более того, для многих представителей нового поколения труд потерял смысл и как средство самореализации. В результате у некоторой части молодого поколения сформировался так называемый социальный пессимизм, который можно рассматривать с позиции неверия в возможность самореализации и нахождения интересной и содержательной работы, оплачиваемой в соответствии с затраченными усилиями [13]. В ходе анализа результатов данного опроса нами был выявлен и тот факт, что большинство опрошенных студентов (86\%) хоть и получают профессию учителя, но в будущем видят себя в предпринимательской, управленческой и других профессиональных сферах.

Необходимость поиска и обоснования теоретикометодологического и практического характера стратегии карьеры студента педвуза, базирующегося на взаимосвязи и взаимопроникновении карьерных потребностей, мотивов, целей индивида и интересов общества, что созвучно идеям Е.А. Климова о трех сферах: «хочу», «могу» и «надо» [15], обусловила и актуальность нашего исследования [16, с. 352-356]. Отметим, что по своему содержанию карьера имеет стратегический характер, поскольку она направлена на продвижение работника в будущем.

В этой связи в рамках нашего исследования были проанализированы ценностные карьерные стратегии студенческой молодежи. В качестве диагностического инструмента мы выбрали методику Э. Шейна «Якоря карьеры» (перевод и адаптация В.А. Чикер, В.Э. Винокурова) [17].

Согласно методике Э. Шейн, выделяется восемь основных карьерных стратегий, так называемых «якорей»: 1 - профессиональная компетентность;
2 - менеджмент; 3 - автономия (независимость); 4 - стабильность; 5 - служение; 6 - вызов; 7 - интеграция стилей жизни; 8 - предпринимательство [18, с. 353-359].

Выборка составила 50 студентов 4-5 курсов. Итак, преобладающими карьерными стратегиями являются (рис. 1): стабильность работы (45\%), стабильность места жительства (29\%), менеджмент (14\%), интеграция стилей жизни (12\%).

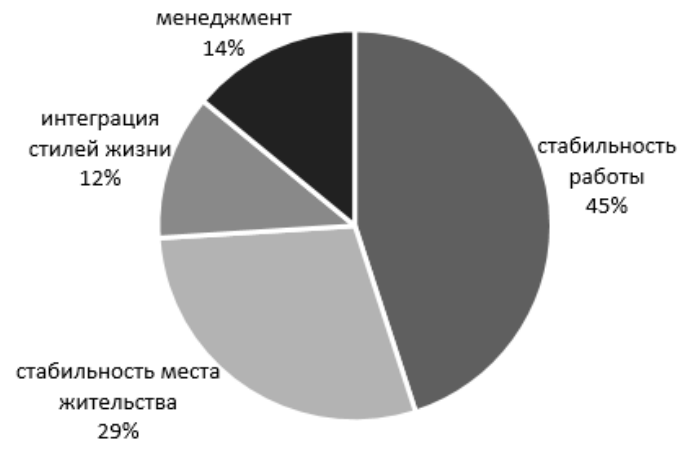

Рисунок 1 - Результаты диагностирования респондентов по методике Э. Шейна «Якоря карьеры»

Интерес для нас представляет тот факт, что многие студенты предпочитают в качестве ведущей стратегию «стабильность работы». Данная стратегия заключается в том, что молодые люди выбирают работу, которая дает стабильность и надежность на длительное время. Они испытывают потребность в безопасности, возможности прогнозирования, ценят социальные гарантии. Вероятно, что данная карьерная стратегия характерна для провинциалов, у которых невысокий уровень притязаний [19, с. 32].

К слову, ни один из опрошенных не назвал в качестве ведущей стратегию «вызов» и «предпринимательство», хотя в своих планах, указанных в методике ЛПП Н.С. Пряжникова, утверждали, что хотят трудиться в сфере предпринимательства. Второй по рангу карьерной стратегией является стратегия «стабильность места жительства». Отметим, что этот результат подтверждается и проведенным нами опросом, согласно которому лишь незначительная часть выборки планирует строить карьеру в столице, большая же часть предпочитает оставаться на своей малой родине - в Поволжье [20]. При этом достаточно значительный процент студентов выбирает также стратегию «интеграция стилей жизни», связанную с желанием реализоваться в различных сферах жизнедеятельности, и стратегию «менеджмент», ориентированную на управление.

Таким образом, подводя итог, отметим, что планирование карьерных стратегий современной молодежью - достаточно сложный процесс, который требует комплексного подхода и в котором органично переплетаются становление профессиональной идентичности личности и формирование его информационной культуры в условиях вхождения нашей страны в глобальное цифровое пространство. Столь серьезная и насущная для общества проблема требует дальнейших научных изысканий.

\section{Список литературы:}

1. Волков Ю.Г., Тарасенко Л.В. Карьерные стратегии студенческой молодежи в современном российском обществе [Электронный ресурс] // http://do.gendocs.ru/docs/index-249607.html. 
2. Микляева А.В., Румянцева П.В. Социальная идентичность личности: содержание, структура, механизмы формирования: монография. СПб.: Изд-во РГПУ им. А.И. Герцена, 2008. 118 с.

3. Беркутова Д.И. Подготовка учителя к педагогической поддержке профессионального самоопределения школьников: монография. Ульяновск: Издательство «Вектор-С», 2009. 188 с.

4. Головаха Е.И. Жизненная перспектива и профессиональное самоопределение молодежи. К.: Наукова думка, 1988. С. 23.

5. Никитина Н.Н. Становление культуры профессионально-личностного самоопределения учителя: монография. М.: Прометей, МПГУ, 2002. 316 с.

6. Пряжников Н.С. Профессиональное и личностное самоопределение. М., Воронеж, 1996. 256 с.

7. Хурум Р.Ю. Формирование информационной культуры педагога // Политематический сетевой электронный научный журнал Кубанского государственного аграрного университета. 2007. № 26. С. 252-265.

8. Масленникова Н.Н. Становление профессионально-педагогической культуры преподавателя педагогического университета: дис. ... канд. пед. наук. Ростов-на-Дону, 1999. 170 с.

9. Громова Е.М., Беркутова Д.И., Горшкова Т.А. Подготовка современной молодежи к планированию профессиональной карьеры: монография. Ульяновск: УлГПУ, 2013. 170 с.

10. Беркутова Д.И., Ястребова Н.А. Социальноэкономические и профессиональные проблемы выпускников педагогических вузов и молодых учителей // Педагогические традиции народов России и зарубежья: мат-лы междунар. науч.-практ. конф. 910 декабря 2014 / отв. ред. Н.Н. Белухина. Ульяновск: ФГБОУ ВПО «УлГПУ им. И.Н. Ульянова», 2015. C. 19-22.

11. Вербицкий А.А. Активное обучение в высшей школе: контекстный подход: методическое пособие. М.: Высш. шк., 1991. 207 с.

\section{PROFESSIONAL IDENTITY FORMATION AS A FACTOR OF A MODERN UNIVERSITY STUDENT'S CAREER STRATEGY PLANNING}

(C) 2018
12. Семенов В.А. Ценностные ориентации современной молодежи // Социологические исследования. 2007. № 4. С. 37-43.

13. Лутовинов В.И., Радионов Е.Г. Современная молодежь: основные ценности, позиции, ориентиры // Военные знания. 1997. № 6. С. 16-18.

14. Громова Е.М., Беркутова Д.И., Горшкова Т.А. Ценности личности как основа жизненной и профессиональной стратегии [Электронный ресурс] // Coвременные проблемы науки и образования. 2013. № 2. - http://science-education.ru/108-9042.

15. Климов Е.А. Психология профессионального самоопределения: учеб. пособие для вузов. М.: Академия, 2004. 302 с.

16. Беркутова Д.И., Громова Е.М. Карьерные стратегии провинциальной молодежи // Категория «социального» в современной педагогике и психологии: мат-лы 2-й науч.-практ. конф. (заочной) с международным участием. В 2 ч. Ч. 1. 2-3 апреля 2014 г. / отв. ред. А.Ю. Нагорнова. Ульяновск: SIMJET, 2014. С. $352-356$.

17. Почебут Л.Г., Чикер В.А. Организационная социальная психология: уч. пособие. СПб., 2002. 234 с.

18. Ильин Е.П. Дифференциальная психология профессиональной деятельности. СПб.: Питер, 2008. $432 \mathrm{c}$.

19. Беркутова Д.И., Громова Е.М. Педагогическая поддержка молодежи в планировании карьеры. Научно-методическое пособие. Ульяновск: Издатель Качалин Александр Васильевич, 2014. 96 с.

20. Громова Е.М., Беркутова Д.И., Горшкова Т.А. Исследование отношения современных российских студентов к построению профессиональной карьеры [Электронный ресурс] // Современные проблемы науки и образования. 2012. № 3. // http://scienceeducation.ru/103-6307.

\author{
Berkutova Diana Iskanderovna, candidate of pedagogical sciences, \\ associate professor of Mathematical Methods and Technological Education Department \\ Gromova Ekaterina Mikhaylovna, candidate of pedagogical sciences, \\ associate professor of Mathematical Methods and Technological Education Department \\ Gorshkova Tatyana Anatolyevna, candidate of pedagogical sciences, \\ associate professor of Mathematical Methods and Technological Education Department \\ Ulyanovsk State Pedagogical University (Ulyanovsk, Russian Federation)
}

Abstract. The paper focuses the attention of researchers on the problem of formation of modern youth's profes-
sional identity, which, according to the authors, is directly related to the career strategy design. The authors analyze
main theoretical approaches to the essence of the concepts of «professional identity», «personal professional perspec-
tive» and «career strategy». The paper presents the results of the study of modern students' professional plans in the
context of their professional career planning. The experimental sample of respondents was made from the number of
full-time students of Physical, Mathematical and Technological Education Department of the Ulyanovsk State Peda-
gogical University named after I.N. Ulyanov. The respondents' diagnosis was carried out by N.S. Pryazhnikov's
method «Personal professional perspective», which promotes the stimulation of the youth's reflections on complex
worldview life problems, professional choice, building a successful career and provoking individual consultations of
value-semantic nature, as well as E. Shane's method «Anchors of career», which is used to determine the leading
professional motives. The results of the study were subjected to a thorough analysis. The paper contains the results of
diagnostics, proving that personal professional perspective and career strategy are closely interrelated. The obtained
materials can serve as a basis for further development of theoretical and practical aspects of the problem of modern
youth's career strategy design.
Keywords: profession; professional self-determination; professional plans; career strategy; professional identifica-
tion; professional identity; value orientation; information culture; students; N.S. Pryazhnikov's method «Personal
professional perspective»; E. Shane's method «Anchors of career». 